\title{
PENGARUH PENYULUHAN BAHAYA MEROKOK DENGAN PERUBAHAN PENGETAHUAN DAN SIKAP MEROKOK PADA PEKERJA DI PT ELNUSA TBK WAREHOUSE KARANGAMPEL TAHUN 2019
}

\author{
Influence of Counseling from the Dangers of Smoking with Changes in Knowledge and Attitude to \\ Smoking on Workers at PT Elnusa Tbk Warehouse Karangampel in 2019
}

\section{Khanifah $^{1}$, Aman Evendi ${ }^{2}$, Eko Maulana Syaputra}

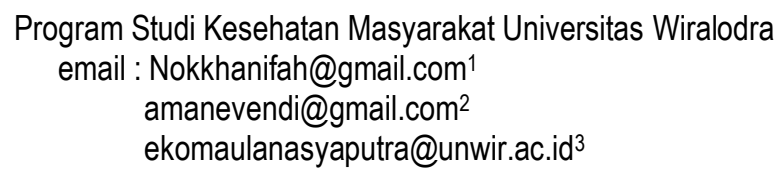

\begin{abstract}
Abstrak
PT Elnusa Tbk Warehouse Karangampel merupakan perusahaan nasional yang menguasai kompetensi di bidang jasa minyak dan gas bumi. Jumlah mayoritas pekerja berjenis kelamin laki - laki mengakibatkan jumlah konsumsi rokok di PT Elnusa Tbk meningkat. Kondisi tersebut mengakibatkan timbulnya berbagai macam penyakit akibat kerja, diantaranya yaitu kasus penyakit jantung koroner yang bisa mengakibatkan kematian mendadak.

Tujuan penelitian ini Untuk mengetahui Pengaruh Penyuluhan Bahaya Merokok Dengan Perubahan Pengetahuan dan Sikap Merokok Pada Pekerja di PT Elnusa Tbk Warehouse Karangampel Tahun 2019.

Metode Penelitian ini termasuk pada penelitian eksperimen semu (Quasi Eksperiment) dengan menggunakan desain one group pretest and posttest design. Penelitian ini dilakukan pada bulan Juli tahun 2019. Populasi dalam penelitian ini berjumlah 35 pekerja. Sampel yang digunakan pada penelitian ini adalah seluruh populasi yang bersedia. Teknik pengumpulan data menggunakan lembar kuesioner dan dianalisis secara univariat dan bivariat dengan uji Wilcoxon. Hasil penelitian yaitu Ada pengaruh antara penyuluhan bahaya merokok dengan perubahan pengetahuan dan sikap merokok pada pekerja di PT Elnusa Tbk Warehouse Karangampel dengan Sig (2-tailed) 0,000 $(<a=0,05)$.

Sebaiknya perusahaan selalu memberikan informasi berupa penyuluhan dengan media visual berupa X-Benner atau Roll Benner untuk pekerjanya baik tentang bahaya-bahaya merokok maupun tentang cara untuk berhenti merokok dan pihak perusahaan memperketat kebijakan tentang larangan merokok di tempat kerja kecuali tempat-tempat khusus yang sudah disediakan dengan cara memberikan sanksi sesuai dengan kesepakatan bersama.
\end{abstract}

Kata kunci: Penyuluhan Bahaya Merokok , Pengetahuan Pekerja, Sikap Pekerja.

\section{Abstract}

PT Elnusa Tbk Werehouse Karangampel is a company that has competence in the field oil and gas services. The majority of male workers resulted an increase in cigarette consumption at PT Elnusa Tbk. These conditions had to the emergence of various occupational disease, including the case of coronary heart disease which can result in sudden death.

This research aims To determine the effect of counseling from the danger of smoking changes in knowledge and smoking attitudes towards workers at PT Elnusa Tbk Warehouse Karangampel in 2019.

This method aims This research was included in quasiexperimental research (Quasi Experiment) using the design of one group pretest and posttest design. This research was conducted in July 2019. The population in this study amounted to 35 workers. The sample used in this study is from the entire population who are willing to. Data collection techniques using questionnaire sheets and analyzed by univariate and bivariate with Wilcoxon test.

The results of this research There is an influence between counseling the dangers of smoking with changes in knowledge and smoking attitudes to workers at PT Elnusa Tbk Warehouse Karangampel with Sig (2-tailed) 0,000 $(<\alpha=0.05)$. The company has should to do always provide information in the form of counseling with visual media in the form X-Benner or Roll Benner for its employes both about the dangers of smoking and how to stop smoking and the company tightens policy on the prohibition of smoking in work places except special places which is already in provide by giving sanktions in accordance with mutual agreement.

Keyword: Counseling on the Danger of Smoking, Knowledge of Workers, Attitude of Workers.

\section{Pendahuluan}

Merokok merupakan kegiatan yang mudah dijumpai dimana saja, merokok seakan telah menjadi bagian dari kehidupan seharihari. Tidak hanya orang tua, remaja bahkan anak-anak ada yang merokok, baik laki-laki maupun perempuan. Keputusan merokok 
timbul salah satunya karena ada pemikiran bahwa dengan merokok akan memperkuat image diri. Rokok dipercaya sebagai sarana pembuktian diri, penghilang kantuk, penambah konsentrasi, dan penamba nafsu makan, serta mengurangi kecemasan. ${ }^{1}$

Menurut organisasi kesehatan dunia menghubungkan hampir 6 juta kematian pertahun disebabkan oleh tembakau. Angka ini diperkirakan meningkat menjadi lebih dari 8 juta kematiann di tahun $2030{ }^{2}$

Indonesia merupakan negara dengan konsumsi rokok terbesar di dunia, yaitu pada urutan ketiga setelah China dan India. Konsumsi tembakau di Indonesia meningkat secara bermakna, karena faktor-faktor meningkatnya pendapatan rumah tangga, pertumbuhan penduduk, rendahnya harga rokok dan mekanisasi industri kretek. Meskipun bahaya rokok sudah banyak diinformasikan namun jumlah rokok di indonesia tidak menurun, bahkan ada kecenderungan meningkat setiap tahun. ${ }^{3}$

Provinsi dengan prevalensi merokok tertinggi di Indonesia adalah Jawa Barat yaitu sebanyak (32,7\%). Sedangkan prevalensi merokok terendah adalah Provinsi Papua yaitu sebanyak $(21,9 \%){ }^{4}$

PT. Elnusa Tbk Warehouse Karangampel merupakan perusahaan nasional yang menguasai kompetensi di bidang jasa minyak dan gas bumi antara lain: Jasa Seismik, Pengeboran dan Pengelolaan Lapangan Minyak. Jumlah mayoritas pekerja berjenis kelamin laki - laki mengakibatkan jumlah konsumsi rokok di PT Elnusa Tbk meningkat. Kondisi tersebut mengakibatkan timbulnya berbagai macam penyakit akibat kerja, diantaranya yaitu kasus penyakit jantung koroner yang bisa mengakibatkan kematian mendadak.

Berdasarkan latar belakang tersebut, penulis tertarik mengambil judul " Pengaruh Penyuluhan Bahaya Merokok dengan Perubahan Perilaku Merokok Pada Pekerja di
PT Elnusa Tbk Warehouse Karangampel Tahun 2019”.

\section{Metode Penelitian}

Jenis penelitian ini adalah penelitian eksperimen semu (quasi eksperiment) dengan menggunakan desain one group pretest and posttest design.

Tabel 1.1 Desain Penelitian

\begin{tabular}{ccc}
\hline & Pretest & Treatment \\
\hline Posttest & & \\
& $\mathrm{T} \longrightarrow \mathrm{X} \longrightarrow \mathrm{T} 2$ \\
\hline
\end{tabular}

Sumber : Suryabrata ${ }^{5}$

Keterangan :

$\mathrm{X}$ : Treatment

T1 : Pretest

T2 : Postest

Penelitian ini dilakukan pada bulan Juli, tahun 2019, pada pekerja di PT Elnusa Tbk Warehouse Karangampel. Dalam penelitian ini metode pengambilan sampel yang digunakan adalah Total Sampling, dalam penelitian ini seluruh pekerja di PT Elnusa Tbk Warehouse Karangampel yang berjumlah 35 laki-laki yang merokok akan diminta untuk menjadi sampel.

Instrumen penelitian yang digunakan adalah kuesioner yang digunakan sebanyak dua kali yaitu untuk pretest dan posttest dengan pembobotan skor yang berbeda setiap variabelnya serta uji statistik menggunakan uji Wilcoxon.

\section{HASIL PENELITIAN}

Hasil penelitian ini terdiri dari hasil analisi univariat dan hasil analisis bivariat sebagai berikut:

A. Hasil Analisis Univariat

1. Distribusi Frekuensi Pengetahuan Pekerja di PT Elnusa Tbk Warehouse Karangampel Sebelum Penyuluhan

Pengetahuan merupakan Tahu atau tidaknya pekerja di PT Elnusa Tbk mengenai 
bahaya merokok sebelum diberikan penyuluhan.

Tabel 1 Distribusi Frekuensi Pengetahuan Pekerja di PT Elnusa Tbk Warehouse Karangampel Sebelum Penyuluhan

\begin{tabular}{cccc}
\hline No. & $\begin{array}{c}\text { Pengetahuan } \\
\text { Pekerja }\end{array}$ & $\begin{array}{c}\text { Frekuens } \\
\text { i }\end{array}$ & (\%) \\
\hline 1. & $\begin{array}{c}\text { Pengetahuan } \\
\text { Baik }\end{array}$ & 14 & 40,0 \\
2. & $\begin{array}{c}\text { Pengetahuan } \\
\text { Cukup }\end{array}$ & 12 & 34,3 \\
& $\begin{array}{c}\text { Pengetahuan } \\
\text { Buruk }\end{array}$ & 9 & 25,7 \\
3. & Total & 35 & 100,0 \\
\hline
\end{tabular}

Sumber : Data Primer

Berdasarkan Tabel 1 dapat dilihat bahwa pekerja di PT Elnusa Tbk Warehouse Karangampel pada tahun 2019 yang memiliki pengetahuan baik tentang bahaya merokok sebelum penyuluhan ada 14 orang $(40,0 \%)$. Sedangkan yang memiliki pengetahuan cukup tentang bahaya merokok sebelum penyuluhan ada 12 orang $(34,3 \%)$, dan yang memiliki pengetahuan buruk tentang bahaya merokok sebelum penyuluhan ada 9 orang $(25,7 \%)$.

2. Distribusi Frekuensi Sikap Pekerja di PT Elnusa Tbk Warehouse Karangampel Sebelum Penyuluhan

Sikap merupakan respon pekerja PT Elnusa Tbk terhadap bahaya merokok sebelum diberikan penyuluhan.

Tabel 2 Distribusi Frekuensi Sikap Pekerja di PT EInusa Tbk Warehouse KarangampelSebelum Penyuluhan

\begin{tabular}{cccc}
\hline No. & $\begin{array}{c}\text { Pengetahuan } \\
\text { Pekerja }\end{array}$ & Frekuensi & (\%) \\
\hline 1. & Sikap Baik & 14 & 40,0 \\
2. & Sikap Cukup & 13 & 37,1 \\
3. & Sikap Buruk & 8 & 22,9 \\
\hline & Total & 35 & 100,0 \\
\hline
\end{tabular}

Sumber: Data Primer
Berdasarkan Tabel 2 dapat dilihat bahwa pekerja di PT Elnusa Tbk Warehouse Karangampel pada tahun 2019 yang memiliki sikap baik tentang bahaya merokok sebelum penyuluhan ada 14 orang (40,0\%). Sedangkan yang memiliki sikap cukup tentang bahaya merokok sebelum penyuluhan ada 13 orang $(37,1 \%)$, dan yang memiliki pengetahuan buruk tentang bahaya merokok sebelum penyuluhan ada 8 orang $(22,9 \%)$.

\section{Distribusi Frekuensi Pengetahuan Pekerja di PT Elnusa Tbk Warehouse Karangampel Sesudah Penyuluhan}

Pengetahuan merupakan Tahu atau tidaknya pekerja di PT Elnusa Tbk mengenai bahaya merokok sesudah diberikan penyuluhan.

Tabel 3 Distribusi Frekuensi Pengetahuan Pekerja di PT Elnusa Tbk Warehouse Karangampel Sesudah Penyuluhan

\begin{tabular}{clcc}
\hline No. & $\begin{array}{l}\text { Pengetahuan } \\
\text { Pekerja }\end{array}$ & Frekuensi & (\%) \\
\hline 1. & $\begin{array}{l}\text { Pengetahuan } \\
\text { Baik }\end{array}$ & 34 & 97,1 \\
2. & $\begin{array}{l}\text { Pengetahuan } \\
\text { Cukup }\end{array}$ & 1 & 2,9 \\
\hline & Total & 35 & 100,0 \\
\hline
\end{tabular}

Sumber: Data Primer

Berdasarkan Tabel 3 dapat dilihat bahwa pekerja di PT Elnusa Tbk Warehouse Karangampel pada tahun 2019 yang memiliki pengetahuan baik tentang bahaya merokok sesudah penyuluhan ada 34 orang $(97,1 \%)$. Namun masih terdapat pekerja yang memiliki pengetahuan cukup tentang bahaya merokok sesudah penyuluhan yaitu 1 orang $(2,9 \%)$.

4. Distribusi Frekuensi Sikap Pekerja di PT Elnusa Tbk Warehouse Karangampel Sesudah Penyuluhan

Sikap merupakan respon pekerja PT Elnusa Tbk terhadap bahaya merokok sesudah diberikan penyuluhan. 
Tabel 4 Distribusi Frekuensi Sikap Pekerja di PT EInusa Tbk Warehouse Karangampel Sesudah Penyuluhan

\begin{tabular}{cccc}
\hline No. & $\begin{array}{c}\text { Pengetahuan } \\
\text { Pekerja }\end{array}$ & Frekuensi & (\%) \\
\hline 1. & Sikap Baik & 34 & 97,1 \\
2. & Sikap Cukup & 1 & 2,9 \\
\hline & Total & 35 & 100,0 \\
\hline
\end{tabular}

Sumber: Data Primer

Berdasarkan Tabel 4 dapat dilihat bahwa pekerja di PT Elnusa Tbk Warehouse Karangampel pada tahun 2019 yang memiliki sikap baik tentang bahaya merokok sesudah penyuluhan ada 34 orang (97,1\%). Namun masih terdapat pekerja yang memiliki sikap cukup tentang bahaya merokok sesudah penyuluhan yaitu 1 orang $(2,9 \%)$.

\section{B. Hasil Analisis Bivariat}

1. Pengaruh Penyuluhan Bahaya Merokok Terhadap Perubahan Pengetahuan Merokok Pada Pekerja di PT Elnusa Tbk Warehouse Karangampel

Hasil analisis statistik dari pengaruh penyuluhan bahaya merokok terhadap perubahan pengetahuan merokok pada pekerja di PT Elnusa Tbk Warehousee Karangampel tahun 2019 adalah sebaga berikut:

Tabel 5 Pengaruh Penyuluhan Bahaya Merokok Terhadap Perubahan Pengetahuan Merokok Pada Pekerja di PT Elnusa Tbk Warehouse Karangampel

Post Test Pengetahuan Pre Test Pengetahuan

Z

Asymp. Sig. (2tailed)

Sumber: Data Primer

Berdasarkan Tabel 5 hasil pengolahan data yang telah dilakukan dengan uji Wilcoxon diketahui bahwa nilai signifikansi $(2-$ tailed $)$ sebesar $0,000<0,05$, maka kita dapat simpulkan bahwa terdapat pengaruh terhadap perubahan pengetahuan dari hasil penyuluhan bahaya merokok pada data pre test dan post test pada pekerja PT Elnusa Tbk. Warehousee Karangampel tahun 2019.

2. Pengaruh Penyuluhan Bahaya Merokok Terhadap Perubahan Sikap Merokok Pada Pekerja di PT Elnusa Tbk Warehouse Karangampel

Hasil analisis statistik dari pengaruh penyuluhan bahaya merokok terhadap perubahan sikap merokok pada pekerja di PT Elnusa Tbk Warehouse Karangampel tahun 2019 adalah sebaga berikut.

Tabel 6 Pengaruh Penyuluhan Bahaya Merokok Terhadap Perubahan Sikap Merokok Pada Pekerja di PT EInusa Tbk Warehouse Karangampel

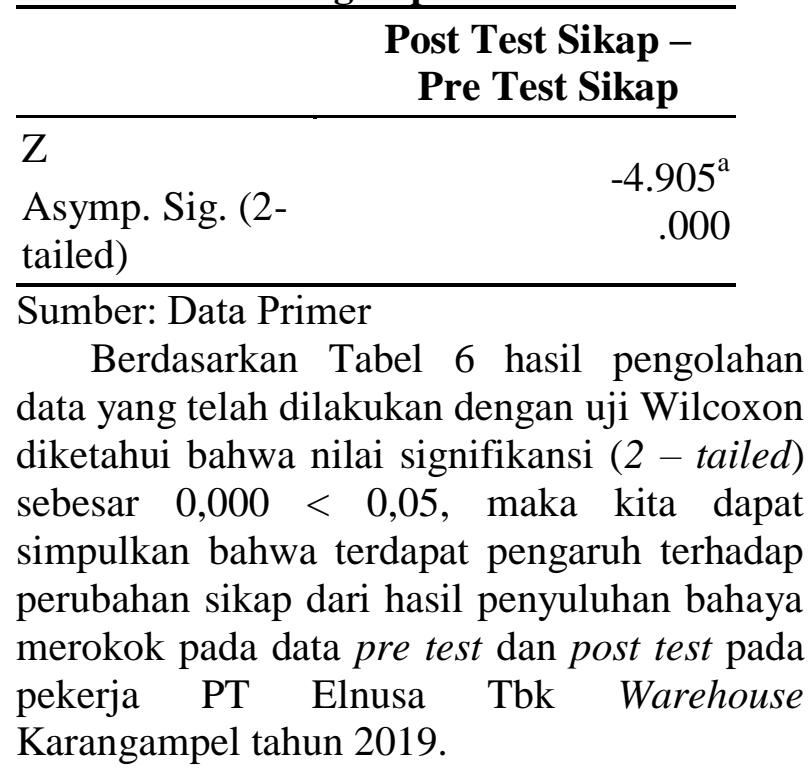

\section{PEMBAHASAN}

A. Pengetahuan Pekerja di PT Elnusa Tbk Warehouse Karangampel Tentang Bahaya Merokok

Menurut Notoatmodjo, pengetahuan (knowledge) merupakan hasil tahu yang terjadi setelah seseorang melakukan pengindraan terhadap suatu objek tertentu. ${ }^{6}$ Dalam penelitian ini pengetahuan pekerja di PT Elnusa Tbk yang diukur yaitu pengetahuan tentang bahaya merokok. 
Pengetahuan pekerja diukur dengan menggunakan kuesioner sebanyak dua kali, yaitu sebelum dan sesudah penyuluhan. Sebelum penyuluhan, yang memiliki pengetahuan baik tentang bahaya merokok ada 14 orang $(40,0 \%)$, sedangkan yang memiliki pengetahuan cukup tentang bahaya merokok ada 12 orang $(34,3 \%)$, dan yang memiliki pengetahuan buruk tentang bahaya merokok ada 9 orang $(25,7 \%)$. Setelah dilakukan penyuluhan, yang memiliki pengetahuan baik tentang bahaya merokok ada 34 orang $(97,1 \%)$, namun masih terdapat pekerja yang memiliki pengetahuan cukup tentang bahaya merokok yaitu 1 orang $(2,9 \%)$ dan tidak terdapat pekerja yang berpengetahuan buruk tentang bahaya merokok.

Rendahnya pengetahuan pekerja tentang bahaya merokok dapat disebabkan oleh berbagai faktor. Menurut Notoatmodjo, salah satu tujuan pendidikan adalah mengembangkan dan meningkatkan pengetahuan. Jadi semakin tinggi tingkat pendidikan seseorang maka semakin banyak pengetahuan yang diperoleh. ${ }^{6}$

Selain pendidikan berdasarkan hasil kuesioner dengan 20 pertanyaan untuk variabel pengetahuan, menunjukkan bahwa pengetahuan responden sebelum dilakukan penyuluhan tentang bahaya merokok dinilai buruk sebanyak 9 orang $(25,7 \%)$. Pengetahuan buruk tersebut didapatkan karena responden belum mengetahui tentang segala sesuatu yang berhubungan dengan rokok dan bahayanya seperti: zat yang terkandung dalam rokok, berapa banyak jumlah zat berbahaya yang terkandung dalam rokok, apa saja penyakit yang ditimbulkan akibat konsumsi rokok, serta kurangnya informasi yang diterima responden tentang dampak konsumsi rokok.

Setelah dilakukan penyuluhan tentang pengetahuan bahaya merokok, menunjukkan bahwa pengetahuan responden sudah dinilai baik dan sudah tidak terdapat responden dengan pengetahuan buruk. Hal tersebut dikarenakan responden sudah mengetahui informasi tentang zat yang terkandung dalam rokok, jumlah zat berbahaya yang terkandung dalam rokok, penyakit yang ditimbulkan akibat konsumsi rokok, serta dampak konsumsi rokok. Faktor yang mempengaruhi pengetahuan salah satunya adalah informasi, dan informasi dalam hal ini adalah penyuluhan bahaya merokok.

Penelitian ini relevan dengan penelitian yang dilakukan oleh Martias ${ }^{7}$, dengan judul pengaruh penyuluhan mengenai bahaya merokok menggunakan media leaflet terhadap perubahan pengetahuan dan sikap siswa di SMPN 3 bintan timur. Hasil analisis uji statistik dengan menggunakan uji Wilcoxon pada pengetahuan responden didapatkan nilai signifikan sebesar 0.001. Nilai signifikan lebih kecil dari alfa $(0,001<0,05)$ maka Ho ditolak dan Ha diterima. Dapat disimpulkan bahwa ada pengaruh signifikan pemberian penyuluhan mengenai bahaya merokok dengan menggunakan media Leaflet terhadap perubahan tingkat pengetahuan siswa Sekolah Menengah Pertama Negeri 3 Bintan Timur.

Penelitian ini juga relevan dengan penelitian yang dilakukan oleh Sulastri ${ }^{8}$, hasil penelitian menunjukkan bahwa rata-rata skor pengetahuan responden sebelum dilakukan intervensi promosi kesehatan adalah 18,40 sedangkan hasil skor rata-rata pengetahuan sesudah dilakukan intervensi promosi kesehatan adalah 18,87. Dari hasil analisis statistik Paired-samples T-test diperoleh nilai probabilitas (Pvalue) sebesar 0,000. Hal ini berarti pada derajat kepercayaan $95 \%(\alpha=0,05)$ nilai Pvalue $<0,05$ maka dapat disimpulkan ada perbedaan pengetahuan remaja sebelum dan sesudah promosi kesehatan tentang dampak rokok pada anak sekolah di SMPN 1 Klari Kabupaten Karawang.

\section{B. Sikap Pekerja di PT Elnusa Tbk Warehouse Karangampel Tentang Bahaya Merokok}

Menurut Notoatmodjo, mengemukakan bahwa sikap (attitude) merupakan reaksi atau respon yang masih tertutup dari seseorang 
terhadap stimulus atau obyek. ${ }^{6}$ Dalam penelitian ini, sikap pekerja PT Elnusa Tbk yang menjadi objek pengukuran yaitu mencakup reaksi atau respon terhadap bahaya merokok.

Sebagaimana pengukuran pada pengetahuan pekerja, sikap pekerja juga diukur dengan menggunakan kuesioner sebanyak dua kali, yaitu sebelum dan sesudah penyuluhan. Sebelum penyuluhan, yang memiliki sikap baik tentang bahaya merokok ada 14 orang $(40,0 \%)$, sedangkan yang memiliki sikap cukup tentang bahaya merokok ada 13 orang $(37,1 \%)$, dan yang memiliki sikap buruk tentang bahaya merokok ada 8 orang $(22,9 \%)$. Setelah dilakukan penyuluhan, yang memiliki sikap baik tentang bahaya merokok ada 34 orang $(97,1 \%)$, namun masih terdapat pekerja yang memiliki sikap cukup tentang bahaya merokok yaitu 1 orang (2,9\%), dan tidak terdapat pekerja yang memiliki sikap buruk tentang bahaya merokok.

Berdasarkan hasil kuesioner dengan 10 pertanyaan untuk variabel sikap, menunjukkan bahwa sikap responden sebelum dilakukan penyuluhan tentang bahaya merokok dinilai buruk sebanyak 8 orang $(22,9 \%)$. sikap yang dimaksud dalam penelitian ini adalah sikap sebelum dilakukan penyuluhan tentang bahaya merokok, pertanyaan-pentanyaan yang diberikan kepada responden bersifat negatif dan positif terkait konsumsi rokok. Salah satu faktor yang mempengaruhi pembentukan sikap adalah pengetahuan. Diketahui bahwa pengetahuan responden sebelum dilakukan penyuluan masih ada yang dinilai buruk, kurangnya informasi yang diterima responden terkait rokok dan dampaknya berpengaruh terhadap rendahnya sikap responden terhadap bahaya rokok. Hal ini sesuai dengan teori yang dikemukaan oleh Notoatmodjo, bahwa semakin baik tingkat pengetahuan maka akan

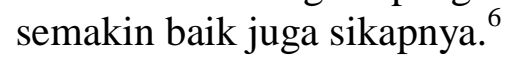

Setelah dilakukan penyuluhan tentang sikap terkait bahaya rokok, menunjukkan bahwa sikap responden sudah dinilai baik dan sudah tidak terdapat responden dengan sikap yang buruk. Hal tersebut dikarenakan responden sudah mendapatkan informasi terkait rokok dan dampaknya. Salah satu komponen yang membentuk sikap diantaranya adalah keyakinan atau kepercayaan terhadap objek. Setelah mendapatkan informasi terkait rokok dan dampaknya dalam tubuh, maka responden memiliki pendapat

Hasil penelitian ini sama dengan penelitian yang dilakukan oleh Rusmilawaty, dengan judul pengaruh penyuluhan metode ceramah tentang bahaya rokok terhadap perubahan sikap perokok aktif. ${ }^{9}$ Hasil analisis uji statistik dengan menggunakan uji Pairedsample T-Test didapatkan hasil bahwa $\mathrm{p}=$ 0,000 maka Ho ditolak yang berarti ada perubahan sikap sebelum dan setelah diberikan penyuluhan dengan selisih rerata sikap 9,58. Hal ini berarti penyuluhan kesehatan dapat mempengaruhi sikap seseorang,

Selanjutnya penelitian yang dilakukan oleh Martias ${ }^{7}$, dengan judul pengaruh penyuluhan mengenai bahaya merokok menggunakan media leaflet terhadap perubahan pengetahuan dan sikap siswa di SMPN 3 bintan timur. Hasil analisis hasil uji Wilcoxon pada sikap responden didapatkan nilai signifikan sebesar 0.000 .Nilai signifikan lebih kecil dari alfa $(0,000<0,05)$ maka Ho ditolak dan Ha diterima. Dapat disimpulkan bahwa ada pengaruh signifikan pemberian penyuluhan mengenai bahaya merokok dengan menggunakan media Leaflet terhadap perubahan sikap siswa Sekolah Menengah Pertama Negeri 3 Bintan Timur.

\section{Pengaruh Penyuluhan Bahaya Merokok Terhadap Perubahan Pengetahuan dan Sikap Merokok Pada Pekerja di PT EInusa Tbk Warehouse Karangampel}

Salah satu strategi untuk memperoleh perubahan pengetahuan dan sikap menurut WHO yang dikuti Notoatmodjo ${ }^{10}$ adalah dengan memberikan informasi untuk meningkatkan pengetahun sehingga menimbulkan kesadaran dan pada akhirnya 
seseorang akan merubah sikapnya sesuai dengan pengetahuannya tersebut. Salah satu upaya pemberian informasi yang dapat dilakukan adalah dengan penyuluhan.

Berdasarkan hasil penelitian, diketahui adanya peningkatan skor pengetahuan dan sikap antara sebelum dan sesudah penyuluhan. Hal ini menunjukkan adanya pengaruh penyuluhan terhadap perubahan pengetahuan dan sikap. Adapun secara statistik (uji Wilcoxon ), dihasilkan nilai Sig (2-tailed) yaitu sebesar 0,000. Artinnya, pada alpha 0,05 terdapat pengaruh penyuluhan yang bermakna (signifikan) terhadap perbaikan pengetahuan dan sikap pekerja terkait bahaya merokok.

Dengan hasil peningkatan skor baik pengetahuan maupun sikap pekerja tentang bahaya merokok menunjukan bahwa penyuluhan tentang bahaya merokok cukup efektif dan efisien serta memberikan pengaruh untuk meningkatkan pengetahuan dan sikap pekerja dalam jangka waktu yang singkat dan sesuai teori yang sudah ada.

Menurut Lucie ${ }^{11}$, penyuluhan sebagai proses perubahan pengetahuan dan sikap itu tidak mudah. Dalam proses perubahan pengetahuan dan sikap, sasaran daharapkan untuk berubah bukan semata-mata hanya karena pengetahuannya bertambah. Namun, diharapkan juga terjadi perubahan sikap yang positif, yang lebih baik, produktif dan menguntungkan.

Pada saat proses penyuluhan peneliti menggunakan metode satu arah. Metode satu arah dilakukan dengan presentasi menggunakan power point dan pembagian leaflet yang sudah dibuat oleh peneliti. Dengan penyuluhan ini, peneliti berasumsi bahwa informasi yang diberikan dapat memberikan pengaruh yang baik terhadap perubahan pengetahuan dan sikap pekerja terkait bahaya merokok.

Dalam tempo setelah penyuluhan hingga dilakukan post test, pekerja bisa saja mendapatkan paparan informasi dari sumber lain yang juga dapat berpengaruh terhadap pengetahuan dan sikap pekerja terkait bahaya merokok. Hal ini memang sulit dikontrol mengingat media pada saat ini memberikan kemudahan dalam mengakses informasi. Untuk itu, peneliti berusaha meminimalisir hal tersebut dengan cara mengadakan post test pada tempo yang relatif pendek yaitu satu minggu setelah penyuluhan dan hal tersebut mampu membuat pekerja tidak mendapatkan paparan informasi dari sumber lain, sehingga hasil penelitian menunjukkan bahwa ada pengaruh positif terhadap perubahan pengetahuan dan sikap pekerja terkait bahaya merokok setelah dilakukan penyuluhan.

\section{KESIMPULAN}

Berdasarkan penelitian yang telah dilakukan, dapat diambil kesimpulan sebagai berikut:

1. Ada pengaruh antara penyuluhan bahaya merokok dengan perubahan pengetahuan merokok pada pekerja di PT Elnusa Tbk Warehouse Karangampel dengan Sig (2tailed) $0,000(<\alpha=0,05)$.

2. Ada pengaruh antara penyuluhan bahaya merokok dengan perubahan sikap merokok pada pekerja di PT Elnusa Tbk Warehouse Karangampel dengan Sig (2-tailed) 0,000 $(<\alpha=0,05)$.

\section{SARAN}

Berdasarkan penelitian yang telah dilakukan, dapat diambil kesimpulan sebagai berikut:

1. Sebaiknya perusahaan selalu memberikan informasi berupa penyuluhan dengan media visual berupa X-Benner atau Roll Benner untuk pekerjanya baik tentang bahaya-bahaya merokok maupun tentang cara untuk berhenti merokok.

2. Pihak perusahaan memperketat kebijakan tentang larangan merokok di tempat kerja kecuali tempat-tempat khusus yang sudah disediakan dengan cara memberikan sanksi sesuai dengan kesepakatan bersama. 


\section{DAFTAR PUSTAKA}

1. Amalia, M,N., 2018, Analisis Pengaruh Konsumsi Rokok Terhadap Produktivitas Tenaga Kerja di Indonesia, Skripsi, Program Studi Pendidikan Ekonomi Jurusan Pendidikan Ekonomi Fakultas Ekonomi Universitas Negeri Yogyakarta (UNY), Yogyakarta.

2. World Health Organization, 2015, Global Youth Tobacco Survey Gyts Indonesia Report 2014, Jakarta.

3. Kementerian Kesehatan, 2012, Bunga Rampai Fakta Tembakau dan Permasalahannya Di Indonesia (Tobacco Control Support Centre) Tahun 2012, Jakarta.

4. Kementerian Kesehatan, 2013, Riset Kesehatan Dasar; Riskesdas, Jumalah Perokok Di Indonesia, Jakarta : Balitbang Kemenkes RI

5. Suryabrata, S., 2011, Psikologi Pendidikan, Jakarta : PT. Raja Grafindo Persada.

6. Notoatmodjo, S., 2007, Pendidikan dan Perilaku Kesehatan, Jakarta : Rineka Cipta.
7. Martias, I dan Nursamsi, S., 2017, Pengaruh Penyuluhan Mengenai Bahaya Merokok Menggunakan Media Leaflet Terhadap Perubahan Pengetahuan dan Sikap Siswa di SMPN 3 Bintan Timur. Jurnal Kesmas Jambi (JKMJ) Vol. 1, No. 2, September 2017.

8. Sulastri dan Rindu, 2019, Perbedaan Pengetahuan dan Sikap Remaja Sebelum dan Sesudah Promosi kesehatan Tentang Dampak Rokok, Jurnal Ilmu Kesehatan Masyarakat Vol. 08, No. 02, Juni 2019.

9. Rusmilawaty, 2016, Pengaruh Penyuluhan Metode Ceramah Tentang Bahaya Rokok Terhadap Perubahan Sikap Perokok Aktif. Jurnal Vokasi Kesehatan, Volume II Nomor 2 Juli 2016, Hal. 113 118.

10. Notoatmodjo, S., 2003, Pendidikan dan Perilaku Kesehatan, Rineka Cipta : Jakarta.

11. Lucie, S., 2005, Teknik Penyuluhan dan Pemberdayaan Masyarakat, Bogor : Ghalia Indonesia. 